\title{
Predicting lesion size during focused ultrasound thalamotomy: a review of 63 lesions over 3 clinical trials
}

\author{
Aaron E. Bond, MD, PhD, and W. Jeffrey Elias, MD \\ Department of Neurological Surgery, University of Virginia Health System, Charlottesville, Virginia
}

OBJECTIVE The goal of this study was to improve the predictability of lesion size during focused ultrasound (FUS) thalamotomy procedures.

METHODS Treatment profiles and T2-weighted MRI (T2 MRI) studies obtained in 63 patients who participated in 3 clinical trials of FUS thalamotomy from February 2011 to March 2015 were reviewed retrospectively. Four damage estimate models were compared with lesion sizes measured on postprocedural T2 MRI. Models were based on $54^{\circ} \mathrm{C} \times 3 \mathrm{sec}-$ onds, 240 cumulative equivalent minutes at $43^{\circ} \mathrm{C}$, and simple thermal threshold analysis, which recorded the maximum diameter that reached a temperature of at least $51^{\circ} \mathrm{C}$ and $54^{\circ} \mathrm{C}$. Energy requirements per ${ }^{\circ} \mathrm{C}$ thermal rise above $37^{\circ} \mathrm{C}$ were also recorded.

RESULTS Lesion diameters from T2 MRI correlated poorly from the day of the procedure to day 1 postprocedure (mean increase $78 \%$ [SD 79\%]). There was more predictability of lesion size from day 1 to day 30 , with a mean reduction in lesion diameter of $11 \%$ (SD 24\%). Of the 4 models tested, the most correlative model to day 1 findings on T2 MRI was a $51^{\circ} \mathrm{C}$ threshold. The authors observed an increase in the energy requirement for each subsequent treatment sonication, with the largest percentage increase from treatment sonication 1 to treatment sonication 2 (mean increase $20 \%$ in energy required per ${ }^{\circ} \mathrm{C}$ increase in temperature above $37^{\circ} \mathrm{C}$ ).

CONCLUSIONS At the margins, $51^{\circ} \mathrm{C}$ temperature threshold diameters correlated best to lesion diameters measured at day 1 with T2 MRI. The lesion size from T2 MRI decreases from day 1 to day 30 in a predictable manner, much more so than from the day of the procedure to day 1 postprocedure. Energy requirements per ${ }^{\circ} \mathrm{C}$ rise above $37^{\circ} \mathrm{C}$ continuously increase with each successive sonication.

https://thejns.org/doi/abs/10.3171/2017.11.FOCUS17623

KEY WORDS focused ultrasound; thalamotomy; thermal dose; tremor

$\mathrm{F}$ OCUSED ultrasound (FUS) thalamotomy was recently approved by the FDA for the treatment of essential tremor (ET), using a commercially approved MRguided FUS system (ExAblate 4000; InSightec Ltd.), and is under investigation for other applications. ${ }^{9}$ However, the technology is still relatively new and the ability to reliably predict lesion size during the procedure is still evolving. Thermal lesion size is currently estimated from both a peak temperature of $54^{\circ} \mathrm{C}$ for 3 seconds and a 240 cumulative equivalent minutes (CEM) at $43^{\circ} \mathrm{C}$ model.

In this paper we reviewed the results in 63 patients who underwent FUS thalamotomy over 3 clinical trials. Damage estimates from the 2 thermal dose models and simple temperature threshold models were compared with postprocedure MRI studies, and the evolution of the lesioning process was quantified from MRI.

\section{Methods \\ Clinical Trial Data}

Data from 3 previous FUS thalamotomy trials were reviewed retrospectively, with institutional review board

ABBREVIATIONS AC-PC = anterior commissure-posterior commissure; $\mathrm{AP}=$ anteroposterior; $\mathrm{CEM}=$ cumulative equivalent minutes; $\mathrm{ET}=$ essential tremor; FUS = focused ultrasound; RCT = randomized controlled trial; SDR = skull density ratio.

SUBMITTED October 1, 2017. ACCEPTED November 2, 2017.

INCLUDE WHEN CITING DOI: 10.3171/2017.11.FOCUS17623. 

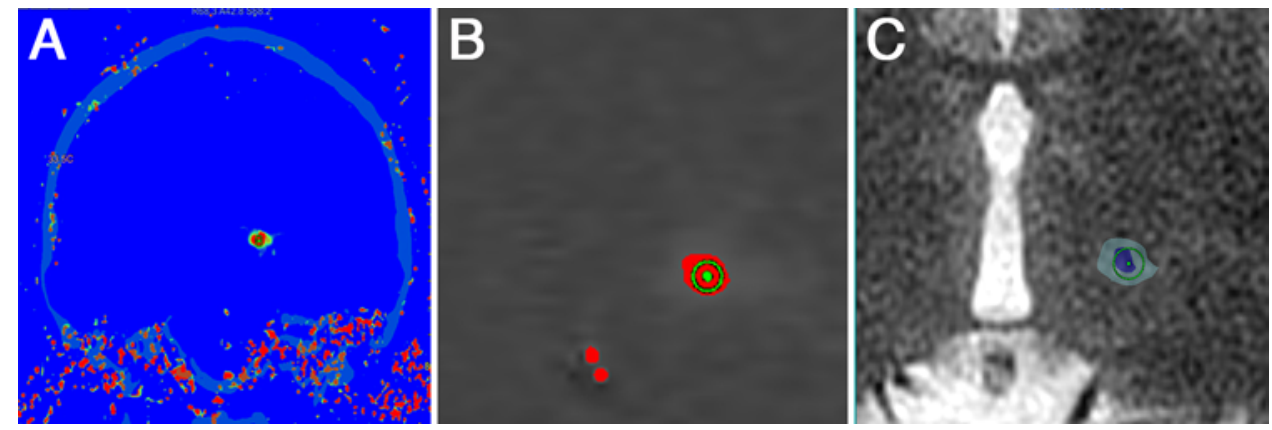

FIG. 1. A: An MR thermometry study obtained during a sonication. B: Example of an image obtained using temperature thresholding. Area in red represents the area that reached a minimum defined temperature. Measurements of the diameter of this area were used in the $51^{\circ} \mathrm{C}$ and $54^{\circ} \mathrm{C}$ temperature threshold models. C: Example of image obtained using the $54^{\circ} \mathrm{C} \times 3$ seconds model (purple), and the $240 \mathrm{CEM}$ at $43^{\circ} \mathrm{C}$ model (slate gray).

approval. The first trial was an open-label, pilot study conducted in 15 patients with ET in 2011. ${ }^{3}$ The second ET trial was a randomized sham-controlled trial (RCT), with 14 patients treated in the blinded phase and another 9 treated during the open-label extension period. ${ }^{5}$ The last was an RCT that was a pilot study of 25 patients treated for tremor-dominant Parkinson disease. ${ }^{1}$ Although the RCTs included multiple sites, only the patients treated at the University of Virginia were included in this analysis. Targeting and techniques for creating an FUS thalamotomy were consistent among all 3 trials, for a total of 63 patients treated with FUS thalamotomy over 4 years. The clinical trials were registered with ClinicalTrials.gov database (http://clinicaltrials.gov), and their registration nos. are NCT01304758, NCT01827904, and NCT01772693.

\section{The FUS Thalamotomy Procedure}

All patients underwent unilateral FUS thalamic lesioning of the ventralis intermedius nucleus by using the ExAblate 4000 midfrequency head transducer (InSightec Ltd.) operating at $710 \mathrm{kHz}$. Details of the procedure have been described previously., ${ }^{2,3-7}$ This system calculates the temperature change from a baseline of $37^{\circ} \mathrm{C}$ (the assumed temperature of the brain parenchyma) during the procedure with voxel-based MR thermometry in predesignated 2D planes, which is used to adjust subsequent sonication parameters and location to obtain an adequate lesion size at a prespecified target (Fig. 1A).

\section{Sonication Temperatures and Thermal Dose Estimates}

The system has a playback mode, which was used to review the treatments. Care was taken to ensure that background temperature windows were drawn consistently in all patients, and were redrawn as necessary. Peak voxel temperature, average peak voxel temperature, target location relative to the posterior commissure (PC), sonication power, and sonication time were recorded for each sonication, which reached a background corrected average temperature of at least $50^{\circ} \mathrm{C}$. At the peak temperature time point (typically the end of the sonication duration), the temperature threshold of the viewer was adjusted to a desired temperature $\left(51^{\circ} \mathrm{C}\right.$ as an example) for assessment of how much area achieved, at a minimum, the desired temperature. These $2 \mathrm{D}$ threshold temperature images were used to measure the maximum diameter of tissue that exceeded the set temperature threshold in the anteroposterior (AP), lateral, and superoinferior directions (Fig. 1B); this dimension is recorded as the temperature threshold diameter. The plane of the thermal map was chosen at the time of treatment. For axial temperature maps, both the AP and lateral dimensions were recorded. To facilitate comparisons to axial MRI, when coronal or sagittal planes were used, coronal lateral dimensions and sagittal AP dimensions were included in the final analysis, and superoinferior dimensions were recorded but not used. Temperature threshold diameters were recorded using a $54^{\circ} \mathrm{C}$ and a $51^{\circ} \mathrm{C}$ threshold set point for all patients. Thresholds of $54^{\circ} \mathrm{C}$ and $51^{\circ} \mathrm{C}$ were chosen to closely match the previous $54^{\circ} \mathrm{C} \times 3$ seconds model, and were based on early observations of correlation of lesion size with $51^{\circ} \mathrm{C}$. All measurements were superimposed on top of each other to achieve a maximum diameter of tissue that reached the threshold temperature, accounting for changes made to the target location during subsequent sonications. As an example, if sonication 7 had a temperature threshold diameter of 4 $\mathrm{mm}$ that reached at least $51^{\circ} \mathrm{C}$ and sonication 8 , which was at the same target, had $5 \mathrm{~mm}$, then the final temperature threshold diameter for $51^{\circ} \mathrm{C}$ would be recorded as $5 \mathrm{~mm}$. If sonication 8 was translated $1 \mathrm{~mm}$, then the final temperature threshold diameter for $51^{\circ} \mathrm{C}$ would be recorded as 5.5 $\mathrm{mm}[(4 \mathrm{~mm} \div 2)+1 \mathrm{~mm}$ translation $+(5 \mathrm{~mm} \div 2)]$.

Tissue damage estimates performed using 2 algorithms were also calculated by the system. The first algorithm records the voxels that reached $54^{\circ} \mathrm{C}$ for at least 3 seconds, and the second algorithm uses the concept of thermal dose and calculates the voxels that reach $240 \mathrm{CEM}$ at $43^{\circ} \mathrm{C}$ (Fig. 1C). The damage estimate from each algorithm was recorded at the completion of each treatment session by measuring the maximum AP and lateral diameter in the axial plane. In the event that the thermal plane during the final sonication was in the coronal or sagittal plane, then only the lateral (coronal) or AP (sagittal) dimensions were used in the final analysis.

In summary, 4 thermal damage estimate predictive models were recorded retrospectively from the temperature measures in the workstation, as follows. 1) The $51^{\circ} \mathrm{C}$ threshold: amount of tissue heated beyond $51^{\circ} \mathrm{C}$ during a sonication; 2) the $54^{\circ} \mathrm{C}$ threshold: amount of tissue heated beyond $54^{\circ} \mathrm{C}$ during a sonication; 3) $54^{\circ} \mathrm{C} \times 3$ seconds: 


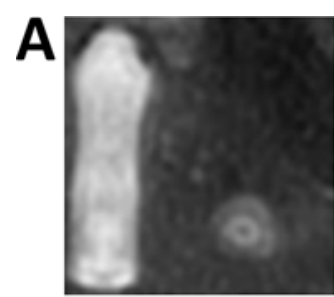

Day 0

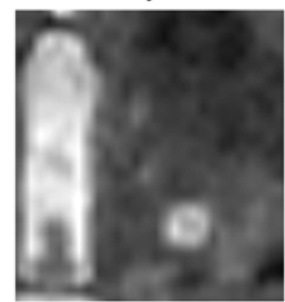

Day 30

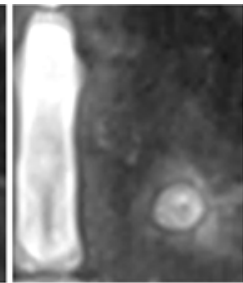

Day 1

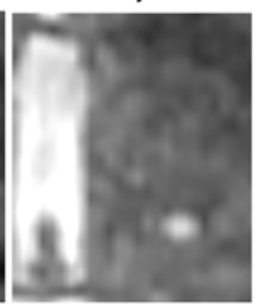

1 Year
B

Change in lesion diameter from Day 0 to Day 1 and Day 1 to Day 30

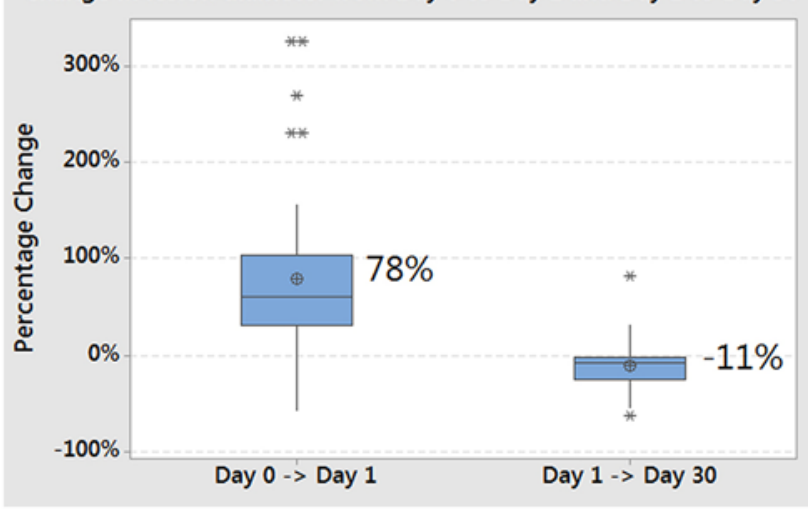

FIG. 2. A: The T2 MRI evolution over time. Diameter measurements in the AC-PC plane were used when correlating to thermal models. Lesion size evolves over time, with mean zone 2 areas of $9.6 \mathrm{~mm}^{2}$ (day 0), $21.6 \mathrm{~mm}^{2}$ (day 1), $20.4 \mathrm{~mm}^{2}$ (day 30 ), and 10.7 $\mathrm{mm}^{2}$ (1 year). B: Box-and-whisker plot showing the mean percentage change in zone 2 lesion diameter from the day of the procedure (day 0 ) to day 1 , and from day 1 to day 30 . Asterisks represent outliers.

amount of tissue heated to $54^{\circ} \mathrm{C}$ for a minimum of $3 \mathrm{sec}-$ onds; and 4) $240 \mathrm{CEM}$ at $43^{\circ} \mathrm{C}$ : amount of tissue heated to a thermal dose of $240 \mathrm{CEM}$ at $43^{\circ} \mathrm{C}$.

\section{Lesion Size Measurement From MRI}

Postprocedure T2-weighted MRI (T2 MRI) studies were reviewed and measured in the axial plane at the level of the anterior commissure-posterior commissure (ACPC) line (Fig. 2A). Lesions were assessed based on the 3 concentric zones that occur on MRI during the thermal ablation process. ${ }^{4,10}$ Zone 1 represents the hypointense central necrotic core, zone 2 is the surrounding T2 hyperintense cytotoxic edema region, and zone 3 is the less hyperintense $\mathrm{T} 2$ region corresponding to perilesional edema that resolves rapidly over time. The AC-PC length, lesion center relative to the $\mathrm{PC}$, and the lateral and $\mathrm{AP}$ diameter of regions 1 and 2 were recorded in the AC-PC plane. The MR images were obtained on the day of the procedure, day 1, day 30, and day 90 during the open-label ET trial. For the ET RCT, MR images were obtained on the day of the procedure and at 1-year follow-up. For the ET RCT open-label extension, they were obtained on day 1. For the tremor-dominant Parkinson disease RCT, MR images were obtained on the day of the procedure, day 1, day 30 , and at 1 year.

The lesion diameters observed on MRI in the AC-PC plane were compared with the temperature threshold contour maps and the workstation-simulated damage estimates with linear regression. Change in lesion size over time was calculated from MRI results by using paired $t-$ tests.

The amount of energy required per ${ }^{\circ} \mathrm{C}$ rise in temperature $\left(\right.$ Energy $\left./{ }^{\circ} \mathrm{C}\right)$ was calculated for each sonication, which reached a maximum background corrected average temperature of at least $50^{\circ} \mathrm{C}$ with the following formula: Energy $/{ }^{\circ} \mathrm{C}=($ Sonication power $*$ Sonication time $) /$ (Max Average Temp $-37^{\circ} \mathrm{C}$ ). The percentage increase in Energy $/{ }^{\circ} \mathrm{C}$ from the preceding sonication was calculated as follows: Percentage increase in Energy $/{ }^{\circ} \mathrm{C}_{(\mathrm{n})}=$ $\left[\right.$ Energy $/{ }^{\circ} \mathrm{C}_{(\mathrm{n})}-$ Energy $\left./{ }^{\circ} \mathrm{C}_{(\mathrm{n}-1)}\right] \div\left[\right.$ Energy $\left./{ }^{\circ} \mathrm{C}_{(\mathrm{n}-1)}\right]$.

\section{Statistical Analysis}

Statistical analysis was performed with IBM SPSS Statistics (version 23; IBM Corp.). Statistical significance was set at $\mathrm{p}<0.05$.

\section{Results}

For all lesions, the $51^{\circ} \mathrm{C}$ threshold model predicted mean lesion diameters in the AC-PC plane of $5.1 \mathrm{~mm}$ (SD 1.5 $\mathrm{mm}$, range $1.5-9.5 \mathrm{~mm}$ ); the $54^{\circ} \mathrm{C}$ threshold model predicted mean lesion diameters of $3.1 \mathrm{~mm}$ (SD $3.1 \mathrm{~mm}$, range $0.0-6.3 \mathrm{~mm}$ ); the $54^{\circ} \mathrm{C} \times 3$ seconds model predicted mean lesion diameters of $3.2 \mathrm{~mm}$ (SD $1.5 \mathrm{~mm}$, range $0.0-7.2$ $\mathrm{mm}$ ); and the $240 \mathrm{CEM}$ at $43^{\circ} \mathrm{C}$ model predicted mean lesion diameters of $6.4 \mathrm{~mm}$ (SD $2.0 \mathrm{~mm}$, range $1.5-13.3 \mathrm{~mm}$ ).

Figure 2A demonstrates an example of the MRI lesion evolution over time. In MRI region 2, the mean lesion diameters in the AC-PC plane on the day of the procedure were $3.5 \mathrm{~mm}$ (SD $1.1 \mathrm{~mm}$, range 1.1-6.8 $\mathrm{mm}$ ), on day 1 they were $5.5 \mathrm{~mm}$ (SD $1.6 \mathrm{~mm}$, range $2.0-10.2 \mathrm{~mm}$ ), and on day 30 they were $4.7 \mathrm{~mm}$ (SD $1.3 \mathrm{~mm}$, range 2.3-8.5 $\mathrm{mm})$. Figure $2 \mathrm{~B}$ shows the mean percentage changes in lesion size from the day of the procedure to day 1 , and from day 1 to day 30 . On the day of the procedure the central necrotic region (region 1), the surrounding cytotoxic edema (region 2), and the perilesional edema (region 3 ) are readily apparent. By day 1, region 2 increases by a mean of $78 \%$ (SD 79\%) and the perilesional edema decreases. Region 2 decreases from day 1 to day 30 by $11 \%$ (SD 24\%) and the perilesional edema is no longer present; further reduction is noted by 1 year. The MRI results at 1 year were difficult to visualize in most cases due to cavity collapse, and are not reported. 
TABLE 1. Simple linear regression analysis of day 1 T2-weighted MRI region 2 lesion diameter versus predictive model

\begin{tabular}{lccccccc}
\hline & \multicolumn{7}{c}{ Linear Regression Analysis } \\
\cline { 2 - 6 } Predictive Model & $\mathrm{R}^{2}$ & $\beta$ & $95 \% \mathrm{Cl}$ for $\beta$ & $\mathrm{B}$ & $95 \% \mathrm{Cl}$ for B & $p$ Value \\
\hline $51^{\circ} \mathrm{C}$ threshold & 0.437 & 0.670 & $0.493-0.847$ & 2.056 & $1.102-3.010$ & $<0.001$ \\
\hline $54^{\circ} \mathrm{C}$ threshold & 0.478 & 0.756 & $0.572-0.941$ & 3.177 & $2.551-3.803$ & $<0.001$ \\
\hline $54^{\circ} \mathrm{C} \times 3 \mathrm{sec}$ & 0.217 & 0.437 & $0.243-0.630$ & 4.132 & $3.442-4.821$ & $<0.001$ \\
\hline $240 \mathrm{CEM}$ at $43^{\circ} \mathrm{C}$ & 0.150 & 0.285 & $0.127-0.444$ & 3.697 & $2.637-4.757$ & 0.001 \\
\hline
\end{tabular}

$B=$ bias (intercept); $\beta=$ regression coefficient (slope); $R^{2}=$ coefficient of determination.

Table 1 lists the results of the simple linear regression analysis of the day 1 T2 MRI lesion diameter measured in the AC-PC plane versus the predicted lesion diameter based on 4 predictive models $\left(51^{\circ} \mathrm{C}\right.$ threshold, $54^{\circ} \mathrm{C}$ threshold, $54^{\circ} \mathrm{C} \times 3$ seconds, and $240 \mathrm{CEM}$ at $43^{\circ} \mathrm{C}$ ). The $54^{\circ} \mathrm{C}$ and $51^{\circ} \mathrm{C}$ threshold models had notably higher coefficients of determination $\left(\mathrm{R}^{2}\right)$ and regression coefficients (slope) than the other 2 models. The $51^{\circ} \mathrm{C}$ threshold model had the lowest bias (intercept) of the 3 models. All models had statistically significant regression analysis with $\mathrm{p}$ $<0.05$. Figure 3 is a scatterplot of the day 1 T2 MRI lesion diameter versus the predicted lesion diameter based on the $51^{\circ} \mathrm{C}$ threshold model. Common targeted lesion diameters range between 4 and $6 \mathrm{~mm}$. When analyzing only patients with predicted lesion diameters of 4-6 mm, using the $51^{\circ} \mathrm{C}$ threshold model, the predicted lesion size was 4.9 $\mathrm{mm}$ (SD $0.56 \mathrm{~mm}$ ), and the resulting day 1 lesion diameter was $5.6 \mathrm{~mm}$ (SD $1.2 \mathrm{~mm}$ ). That is, if a target of 4-6 mm was planned based on thermal mapping using the $51^{\circ} \mathrm{C}$ threshold model, one would expect $95 \%$ of actual lesions to fall within $5.6 \mathrm{~mm} \pm 2.4 \mathrm{~mm}$, and $68 \%$ to fall within 5.6 $\mathrm{mm} \pm 1.2 \mathrm{~mm}$.

Figure $4 \mathrm{~A}$ demonstrates the energy required per ${ }^{\circ} \mathrm{C}$ temperature rise over $37^{\circ} \mathrm{C}$ for sonications that reached a maximum average temperature of at least $50^{\circ} \mathrm{C}$-the legend indicates the patients' skull density ratio (SDR).

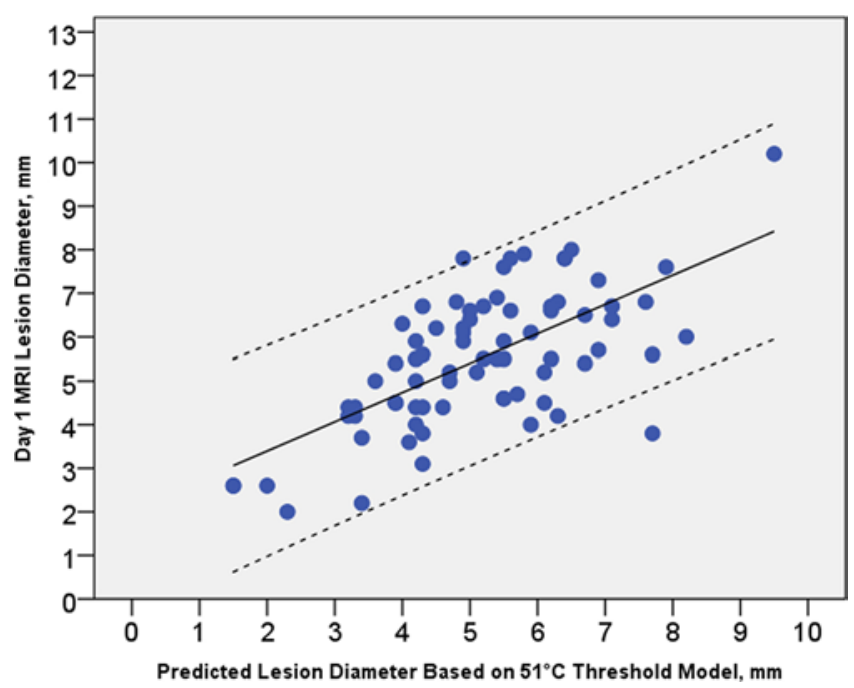

FIG. 3. Scatterplot showing day 1 T2 MRI lesion diameter versus predicted lesion diameter, based on the $51^{\circ} \mathrm{C}$ threshold model. Actual lesion diameter $=0.44[95 \% \mathrm{Cl} 0.49-0.85]{ }^{*}$ Predicted lesion diameter +2.1 $[95 \% \mathrm{Cl} 1.1-3.0], R^{2}=0.437, p<0.001$.
Figure 4B is a plot of the mean percentage increase in energy required per ${ }^{\circ} \mathrm{C}$ temperature rise over $37^{\circ} \mathrm{C}$ for each subsequent sonication that reached a temperature of at least $50^{\circ} \mathrm{C}$. The increase in absolute energy required per ${ }^{\circ} \mathrm{C}$ temperature rise over $37^{\circ} \mathrm{C}$ increased with decreasing SDR; however, the percentage increase in energy with each subsequent sonication was similar for all SDR values. The mean percentage increase in energy required per ${ }^{\circ} \mathrm{C}$ temperature rise over $37^{\circ} \mathrm{C}$, for all SDRs, was $20 \%$ higher during sonication 2, as compared with sonication 1 . The percentage increase gradually decreased with further sonications, and by sonication 5 the mean percentage increase in energy required per ${ }^{\circ} \mathrm{C}$ temperature rise over $37^{\circ} \mathrm{C}$ was $11 \%$, as compared with sonication 4 .

\section{Discussion}

It is important to be able to predict lesion size during thermal ablation procedures like FUS thalamotomy. From this correlation study of thalamic temperature measurements performed using MR thermometry and postprocedural T2-weighted MRI, we found that lesion size is easier to predict from day 1 images than from images obtained during the procedure. The $+78 \%$ change in lesion diameter from the day of the procedure to day 1 had significant variability (SD 79\%), giving us poor confidence in the predictability of MR images obtained on the day of the procedure; however, the change from day 1 to day 30 was relatively small and more consistent $(-11 \%$, SD $24 \%)$. This gave us confidence that we could use the day 1 T2 MR images for our correlations and expect them to correlate well to the MRIs obtained at day 30, which are believed to be mature lesions before collapse of the cavity. ${ }^{10}$ In our current workflow, imaging after the final sonication is often delayed for a few minutes to be evident on T2 MR images. If an MRI study is performed immediately following a treatment, the lesion is often difficult to visualize. It is our routine for all patients receiving FUS thalamotomy to undergo MRI at day 1 and not necessarily other time points, because we have extensively characterized the lesions with MRI in a smaller number of patients, and the postprocedural evolution of the lesion is rather consistent. ${ }^{10}$

The predictive power (or correlation) of temperature estimates for FUS thalamic ablations was determined for 4 different models. The $54^{\circ} \mathrm{C} \times 3$ seconds and the $240 \mathrm{CEM}$ at $43^{\circ} \mathrm{C}$ models had low correlation to the final outcomes. The $54^{\circ} \mathrm{C}$ threshold model had the best $\mathrm{R}^{2}$ value and slope of all models; however, a large bias was still present (3.2 $\mathrm{mm})$. The $51^{\circ} \mathrm{C}$ threshold model had the lowest bias of all models studied $(2.1 \mathrm{~mm})$ and had a similar $\mathrm{R}^{2}$ to that of the 

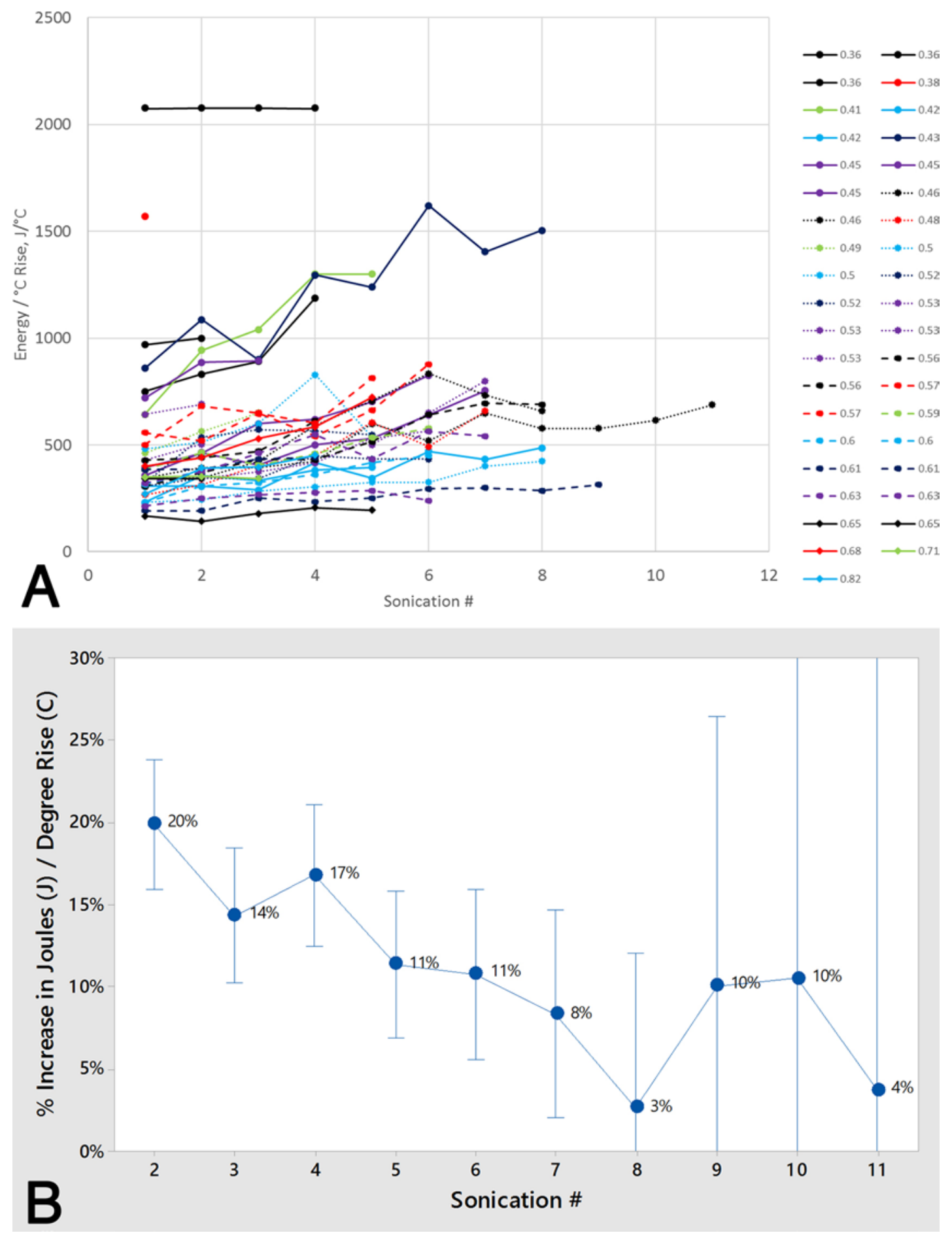

FIG. 4. A: Graph showing the energy required per ${ }^{\circ} \mathrm{C}$ temperature rise versus number of sonications exceeding $50^{\circ} \mathrm{C}$ maximum average temperature. Key indicates patients' SDR. B: Graph showing the mean percentage increase in energy requirement from prior sonication for all SDRs.

$54^{\circ} \mathrm{C}$ model. From the data we collected, we can conclude that at the margins, the $51^{\circ} \mathrm{C}$ threshold data most closely predicts the lesion size observed on day 1 T2 MRI. Previous studies in rabbits demonstrated a peak temperature threshold between $48^{\circ} \mathrm{C}$ and $50.8^{\circ} \mathrm{C}$, which is consistent with our findings at the margins. ${ }^{8}$ It is worth noting that, to achieve a $51^{\circ} \mathrm{C}$ thermal diameter of at least $5 \mathrm{~mm}$ (a rea- sonable lesion size), a peak voxel temperature of $>56^{\circ} \mathrm{C}$ is generally required, which is a common goal during FUS lesioning.

We observed an increase in the energy requirement for each subsequent treatment sonication. The percentage increase in the energy requirement to achieve a given temperature was largest from sonication 1 to sonication 
2 (20\%), and decreased with subsequent sonications. The mechanism for the increase in required energy is unclear and is under investigation.

Limitations of this study include the fact that it was in a single center, retrospective, and that all measurements were performed by a single investigator. Strengths include the large number of patients and the spread in time in which patients were treated.

\section{Conclusions}

In this retrospective review of 63 FUS thalamotomies, lesion size from T2 MRI correlated well from day 1 to day 30 , and can be used to estimate lesion diameters. During the procedure, $51^{\circ} \mathrm{C}$ temperature threshold diameters at the margins correlated most closely to lesion diameters measured on day $1 \mathrm{~T} 2 \mathrm{MRI}$. Energy requirements per ${ }^{\circ} \mathrm{C}$ rise above $37^{\circ} \mathrm{C}$ continuously increase with each successive sonication.

\section{References}

1. Bond AE, Dallapiazza R, Huss D, Warren AL, Sperling $\mathrm{S}$, Gwinn R, et al: A randomized, sham-controlled trial of transcranial magnetic resonance-guided focused ultrasound thalamotomy trial for the treatment of tremor-dominant, idiopathic Parkinson disease. Neurosurgery 63 (Suppl 1):154, 2016 (Abstract)

2. Chang WS, Jung HH, Kweon EJ, Zadicario E, Rachmilevitch I, Chang JW: Unilateral magnetic resonance guided focused ultrasound thalamotomy for essential tremor: practices and clinicoradiological outcomes. J Neurol Neurosurg Psychiatry 86:257-264, 2015

3. Elias WJ, Huss D, Voss T, Loomba J, Khaled M, Zadicario E, et al: A pilot study of focused ultrasound thalamotomy for essential tremor. N Engl J Med 369:640-648, 2013

4. Elias WJ, Khaled M, Hilliard JD, Aubry JF, Frysinger RC, Sheehan JP, et al: A magnetic resonance imaging, histological, and dose modeling comparison of focused ultrasound, radiofrequency, and Gamma Knife radiosurgery lesions in swine thalamus. J Neurosurg 119:307-317, 2013
5. Elias WJ, Lipsman N, Ondo WG, Ghanouni P, Kim YG, Lee $\mathrm{W}$, et al: A randomized trial of focused ultrasound thalamotomy for essential tremor. N Engl J Med 375:730-739, 2016

6. Jeanmonod D, Werner B, Morel A, Michels L, Zadicario E, Schiff G, et al: Transcranial magnetic resonance imagingguided focused ultrasound: noninvasive central lateral thalamotomy for chronic neuropathic pain. Neurosurg Focus 32(1):E1, 2012

7. Lipsman N, Schwartz ML, Huang Y, Lee L, Sankar T, Chapman M, et al: MR-guided focused ultrasound thalamotomy for essential tremor: a proof-of-concept study. Lancet Neurol 12:462-468, 2013

8. McDannold N, Vykhodtseva N, Jolesz FA, Hynynen K: MRI investigation of the threshold for thermally induced bloodbrain barrier disruption and brain tissue damage in the rabbit brain. Magn Reson Med 51:913-923, 2004

9. Weintraub D, Elias WJ: The emerging role of transcranial magnetic resonance imaging-guided focused ultrasound in functional neurosurgery. Mov Disord 32:20-27, 2017

10. Wintermark M, Druzgal J, Huss DS, Khaled MA, Monteith $S$, Raghavan P, et al: Imaging findings in MR imaging-guided focused ultrasound treatment for patients with essential tremor. AJNR Am J Neuroradiol 35:891-896, 2014

\section{Disclosures}

Dr. Elias received clinical or research support for the study described (includes equipment or material) from InSightec Ltd.

\section{Author Contributions}

Conception and design: both authors. Acquisition of data: both authors. Analysis and interpretation of data: both authors. Drafting the article: Bond. Critically revising the article: both authors. Reviewed submitted version of manuscript: both authors. Approved the final version of the manuscript on behalf of both authors: Bond. Statistical analysis: Bond. Administrative/techni$\mathrm{cal} / \mathrm{material}$ support: Elias. Study supervision: Elias.

\section{Correspondence}

Aaron E. Bond: University of Virginia Health System, Charlottesville, VA. ab8nb@hscmail.mcc.virginia.edu. 